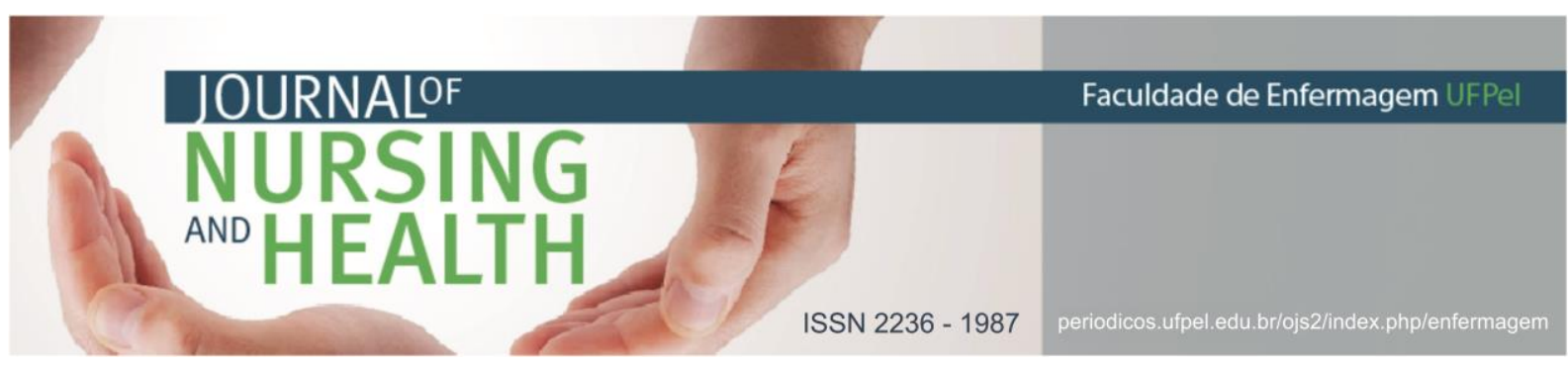

EDITORIAL

\title{
0 eco das vozes roucas dos trabalhadores técnicos de nível médio em enfermagem e a necessidade da escuta sensível
}

\section{The echo from hoarse voices of technical employees of middle level in nursing, and the necessity of sensitive listening}

\section{El eco de voces roncas de trabajadores técnicos de nivel medio en enfermería y la necesidad de escucha sensible}

Silvana Lima VIEIRA ${ }^{1}$

Em estudo multicêntrico recente, com universo de 1,6 milhão de profissionais de enfermagem brasileiros, foi constatado que técnicos de nível médio em saúde (técnicos e auxiliares) compreendem cerca de $80 \%$ do quadro da categoria Enfermagem ${ }^{1}$, com maior crescimento nos postos de trabalho na área da saúde entre os anos de 2009 e 2012. ${ }^{1-3}$

Ainda que esse contingente profissional expressivo esteja inserido no Sistema Único de Saúde (SUS), com atuações igualmente significativa nos setores privado e filantrópico, verifica-se nos dias atuais antigos problemas relacionados com a natureza da sua força de trabalho em saúde como a divisão social do trabalho, subalternidade e feminização da profissão. Problemas estes, historicamente intrínsecos às profissões técnicas de nível médio em saúde e em enfermagem, no qual o reforço da dualidade entre o fazer e o saber no trabalho faz-se presente.

Mesmo em passos curtos, essa dura realidade vêm tomando contornos diferentes e ressoando vozes, ainda que roucas e oprimidas, desse contingente expressivo de trabalhadores.

A atitude de membros da equipe multiprofissional em saúde, que por séculos minimizou e reduziu esses profissionais ao seu trabalho "dito" fragmentado e manual, vê-se agora diante de uma nova realidade educacional e social, revelada pelo aumento da escolaridade desses trabalhadores, acima da exigida para o desempenho de suas atribuições, com cerca de 35,5\% com nível superior incompleto e frequentando cursos em instituições de ensino superior. ${ }^{1}$

Essa nova conjuntura passa a requerer reflexões e ações na cena do trabalho no campo da saúde, com a necessidade de rever o modo do trabalho em equipe, a luta contra a precarização do trabalho desses profissionais- submetidos a dupla/ tripla jornadas de trabalho -, baixos salários, incertezas e riscos de modo a permitir a visibilidade a esses profissionais que, no processo de trabalho em saúde, desenvolvem efetivamente, o cuidado direto ao usuário. ${ }^{3}$

É necessário portanto, dar voz e promover a escuta sensível a esse contingente de trabalhadores de maneira que sejam entendidos e valorizados em seu papel nas

${ }^{1}$ Enfermeira. Doutora em Enfermagem. Docente na Universidade do Estado da Bahia, Salvador, Bahia- Brasil. Email: prof.silvanalimavieira@gmail.com 
relações dialógicas do mundo do trabalho e, dessa forma, reconhecer as potencialidades e limitações da sua força de trabalho nos contextos da saúde.

A escuta sensível ${ }^{4}$ desses trabalhadores poderá levar à compreensão e respeito com presença do outro em nossa vida e no contexto de trabalho proporcionar a interação nas trocas, aprendizados e conhecimento que, individualmente, não seria possível construir. A escuta sensível propõe-se à ação consciente em situação de opressão, implicação dos envolvidos na fala e na escuta e do que surgiu a partir dela. Implica portanto, compreender os técnicos de nível médio em enfermagem como atores/atrizes e também autores no campo do trabalho em saúde. Dessa forma, estabelecer ligações entre as experiências existenciais do outro e a sua formação na busca do saber e do conhecimento e, assim, instalar-se em um certo tipo de relação com o mundo. ${ }^{5}$

Há que se tentar vencer o "tribalismo das profissões"6 e na enfermagem, de maneira a ir contra a tendência de ações isoladas ou mesmo em concorrência cotidiana.

Para tanto, faz-se necessário ir de encontro ao des-interesse dos pesquisadores da área de saúde em desenvolverem estudos voltados aos trabalhadores técnicos de nível médio em enfermagem ${ }^{7}$, de modo que seja estimulado na academia e no mundo do trabalho o pensamento e ação crítica sobre essa temática, de maneira a fortalecer a profissão - Enfermagem - e, consequentemente, a consolidação de um sistema de saúde em que a equipe multiprofissional esteja sensível e atenta às necessidades dos usuários e também dos seus pares, esperançosos diuturnos por escuta e visibilidade.

\section{Referências}

1. Machado MH (Coord.), Aguiar WF, Lacerda WF, Oliveira E, Lemos W, Wermelinger $M$, et. al. Relatório final da Pesquisa Perfil da Enfermagem no Brasil. Rio de Janeiro: NERHUS-DAPS-Ensp/Fiocruz e Cofen; 2015.

2. Nascimento PAM, Maciente NA, Assis LRS. As ocupações de nível técnico que mais geraram empregos entre 2009 e 2012. Rev radar: tecnologia, produção e comércio exterior [internet].2013 jul; 7(27): 21-30.

3. Ramos LA, Carvalho EC, Canini SR. Opinião de auxiliares e técnicos em enfermagem sobre a sistematização da assistência de enfermagem. REE. 2009; 11(1): 39-44.

4. Barbier R. Escuta sensível na formação de profissionais de saúde. Conferência Escola Superior de Ciências da Saúde; 2002; Brasília.

5. Freire. Pedagogia da Esperança: 0 encontro com a pedagogia do oprimido. $54^{\text {a }}$ ed. Rio de Janeiro: Paz e Terra; 2014.

6. Frenk J, Chen L, Bhutta ZA, Cohen J, Crisp N, Evans T, et al. Health professionals for a new century: transforming education to strengthen health systems in aninterdependent world. Lancet. 2010 Dez; 4376(9756):1923-58. 
7. Vieira SL, Silva GTR, Fernandes JD, Bião ACA, Santana MS, Santos TBS. Desinteresse no ensino profissionalizante na produção do Seminário Nacional de Diretrizes para a Educação em Enfermagem. Rev bras enferm. [Internet]. 2014 Fev [acesso em 2017 Mar 27] ; 67( 1 ): 141-148. Disponível em: http://www.scielo.br/scielo.php?script=sci_arttext\&pid=S0034-

71672014000100141\&lng=en. http://dx.doi.org/10.5935/0034-7167.20140019.

Publicação: 2017-04-12 